\title{
Mortality Cut-off Year, National Death Index
}

National Cancer Institute

\section{Source}

National Cancer Institute. Mortality Cut-off Year, National Death Index. NCI Thesaurus.

Code C159714.

The last year of data used in the National Death Index. 